Kalpa Publications in Civil Engineering
Volume 1, 2017, Pages 103-108
$\begin{gathered}\text { ICRISET2017. International Conference on Re- } \\ \text { search and Innovations in Science, Engineering } \\ \text { \&Technology. Selected papers in Civil Engineering }\end{gathered}$

\title{
Experimental Study on Lightweight Concrete with Styrofoam as a Replacement for Coarse Aggregate
}

\author{
Divya Patel ${ }^{1 *}$, Uresh Kachhadia ${ }^{1}$, Mehul Shah ${ }^{1}$ and Rahul Shah ${ }^{1 \dagger}$ \\ ${ }^{1}$ School of Engineering and Technology, Navrachana University, Vadodara, India. \\ divya51195@gmail.com, mehulshah6677@gmail.com, rahuls@nuv.ac. in
}

\begin{abstract}
With the rapid growth in building construction and urbanisation, buildings are getting taller and bigger than ever. In India majority of structures are constructed with the help of concrete resulting into very heavy structures. Heavy loads are one of the limitations for construction of tall buildings. If somehow structures are made lighter, cost of the foundation can also be lowered down. Conventional concrete is one of the main reason in increasing the weight of the buildings. Light weight concrete can be very much effective in reducing the overall weight of the building. In conventional concrete, larger volume comprises of coarse aggregates.In this study, attempt has been made to replace conventional coarse aggregates with Styrofoam which is a very light weight foam. Concrete with different aggregate replacement percentage was tested. The results show very encouraging results for thecompressive strength and density.
\end{abstract}

\section{Introduction}

Generally natural stones such as limestone and granite are used as coarse aggregate in concrete. With the increasing use of concrete in construction, natural resources are heavily exploited. Synthetic Lightweight aggregates can be used as a replacement for coarse aggregates. Use of lightweight concrete permits greater design flexibility, substantial cost savings, reducing dead loads, thinner sections, small structural elements, etc.

Lightweight concrete may be defined as the concrete of substantially lower unit weight than that made of gravel or crushed stone. Ordinary concrete is quite heavy. Thus, if used, it adds considerably to the dead weight of the structure. Lightweight concrete not only reduces the dead weight of the structure but can also act as thermal insulation.

"Under Graduate student

${ }^{\dagger}$ Associate Professor

C.D. Modhera, G.J. Joshi, D. Soni, I.N. Patel, A.K. Verma, L.B. Zala, S.D. Dhiman, D.R. Bhatt, J.M. Rathod, B.C. Goradiya, M.S. Holia and D.K. Patel (eds.), ICRISET2017 (Kalpa Publications in Civil Engineering, vol. 1), pp. 103-108 
Experimental Study on Lightweight Concrete with... D. Patel, U. Kachhadia, M. Shah and R. Shah.

The objectives of this study are as follows:

- To study the basics of Lightweight concrete.

- To find viable replacement for coarse aggregates.

- To cast M30 grade concrete consisting different proportions of replacement material.

- To compare the compressive strength and dry density of concrete.

- To comment on probability of replacement of coarse aggregates with replacement material.

\section{Literature Review}

Lakshmi Kumar Minapu, M K M V Ratnam and Dr. U Rangaraju (2014) [2] have presented experimental investigation consisting of casting and testing of 9 sets of cubes, cylinders and prisms consisting of different proportion of pumice stone used as a replacement to natural coarse aggregate. Each set consisted 4 cubes, 2 cylinders and 2 prisms for determining compressive strength, tensile strength and flexural strength respectively. Pumice stone was used as a partial replacement to natural coarse aggregates in different proportions along with fly ash and silica fumes in varying proportions. Cubes, cylinders and prisms were casted adopting M30 design mix proportions and then cured for 28 days. After 28 days they were tested for compressive strength, tensile strength and flexural strength. From the results it was concluded that light weight aggregate is in no way inferior to natural coarse aggregates and they can be used for construction.

Dr. V Bhaskar Desai and Mr. A. Sathyam (2014) [1] have attempted replacing natural coarse aggregates with lightweight cinder aggregates. Cinder in proportions varying from $0 \%$ to $100 \%$ was used as coarse aggregate forM20 design mix. Various cubes and cylinders were casted and tested for compressive strength, tensile strength, shear strength at the end of 28 days of curing. It was concluded that even after replacing natural aggregates by $75 \%$ the compressive strength was greater than the target strength. Thus cinder can be used as a replacement for natural coarse aggregates.

T. Parhizkar, M. Najimi and A.R. Pourkhorshidi (2011) [3] have presented experimental investigation on the properties of volcanic pumice lightweight aggregates concretes. To this end, two groups of lightweight concrete (lightweight coarse with natural fine aggregates concrete, and lightweight coarse and fine aggregates concrete) are built and the physical/mechanical and durability aspects of them are studied. The results of compressive strength, tensile strength and drying shrinkage show that these lightweight concretes meet the requirements of the structural lightweight concrete.

\section{Methodology}

Styrofoam was selected as a replacement material for coarse aggregates. Styrofoam is a lightweight insulation material designed for various engineering applications such as concrete floor, roadways, rail beds, etc. Samples of definite volume were oven dried for 24 hours to determine the dry density of Styrofoam, which approximately came out to be $33.2 \mathrm{~kg} / \mathrm{m}^{3}$.

Mix design using IS 10262: 2009 method was carried out for M30 grade of concrete. From which proportion of cement, sand, aggregate and water-cement ratio was obtained. Totally six sets of cube i.e. two in each set of dimensions $150 \times 150 \times 150 \mathrm{~mm}$ were casted having $0 \%, 20 \%, 40 \%, 60 \%, 80 \%$ and $100 \%$ replacement of aggregate with Styrofoam by weight.

Non Destructive Rebound Hammer test was performed at the interval of 7, 21 and 28 days. Dry density of the concrete was obtained at the end of 28 days. 


\section{Material Properties and Mix Design}

\subsection{Material Properties}

The materials used for casting of cubes are cement of 53 grade, sand passing through IS $4.75 \mathrm{~mm}$ sieve having specific gravity 2.634 and water absorption $0.72 \%$, natural aggregate having specific gravity 2.841 and water absorption $0.81 \%$ and Styrofoam having specific gravity 0.033 and water absorption $23.33 \%$.

\subsection{Mix Design}

Mix design can be defined as a process of determining relative proportions of cement, sand and aggregate with the object of producing concrete of certain minimum strength and durability as economically as possible. Mix design was carried out using IS:10262-(2009). The mix proportion obtained for normal M30 grade concrete was 1:1.35:2.48 with a water-cement ratio of 0.5 .

\section{Result and Discussion}

\subsection{Compressive Strength}

The cubical specimens were tested for compressive strength at the end of 7, 21 and 28 days using a rebound hammer. The compressive strength of the concrete is tabulated below:

\begin{tabular}{ccccc}
\hline Mix & \% Styrofoam & \multicolumn{3}{c}{$\begin{array}{r}\text { Average Compressive Strength (MPa) at the end } \\
\text { of }\end{array}$} \\
& & 7 Days & 21 Days & 28 Days \\
\hline C-0 & 0 & 22.5 & 32.06 & 39.81 \\
C-20 & 20 & 20.3 & 31.68 & 38.25 \\
C-40 & 40 & 19.6 & 28.62 & 35.56 \\
C-60 & 60 & 18.3 & 27.31 & 34.12 \\
C-80 & 800 & 17.5 & 24.93 & 33.56 \\
C-100 & 100 & 16.4 & 23.52 & 30.5 \\
\hline
\end{tabular}

Table 1: Average Compressive Strength of Concrete 
Experimental Study on Lightweight Concrete with... D. Patel, U. Kachhadia, M. Shah and R. Shah.

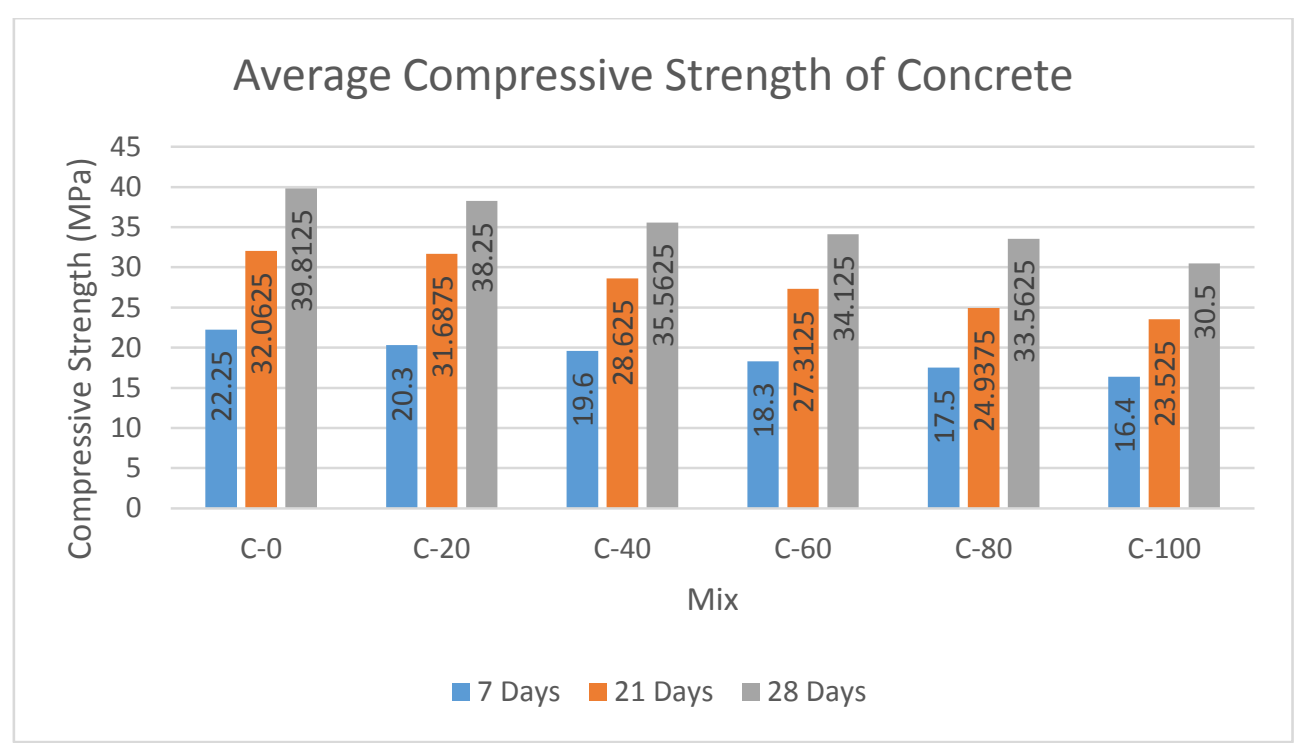

Fig. 1: Average Compressive Strength of Concrete.

From Fig. 1 it can be concluded that compressive strength decreases with the increase in proportion of Styrofoam in the mix

\subsection{Dry Density and Specific Gravity}

Dry density and specific gravity were obtained from dry mass of the cubes at the end of 28 days.

\begin{tabular}{ccccc}
\hline Mix & \% Styrofoam & $\begin{array}{c}\text { Average } \\
\text { mass }(\mathrm{kg})\end{array}$ & $\begin{array}{c}\text { Average } \\
\text { Dry Density } \\
\left(\mathrm{kg} / \mathrm{m}^{3}\right)\end{array}$ & $\begin{array}{c}\text { Average Specific } \\
\text { Gravity }\end{array}$ \\
\hline C-0 & 0 & 8.12 & 2405.92 & 2.406 \\
C-20 & 20 & 7.85 & 2325.92 & 2.326 \\
C-40 & 40 & 7.1 & 2103.7 & 2.104 \\
C-60 & 60 & 6.33 & 1875.55 & 1.875 \\
C-80 & 800 & 5.83 & 1727.41 & 1.727 \\
C-100 & 100 & 4.64 & 1374.81 & 1.375 \\
\hline
\end{tabular}

Table2: Average Dry Density and Specific Gravity 
Experimental Study on Lightweight Concrete with... D. Patel, U. Kachhadia, M. Shah and R. Shah.

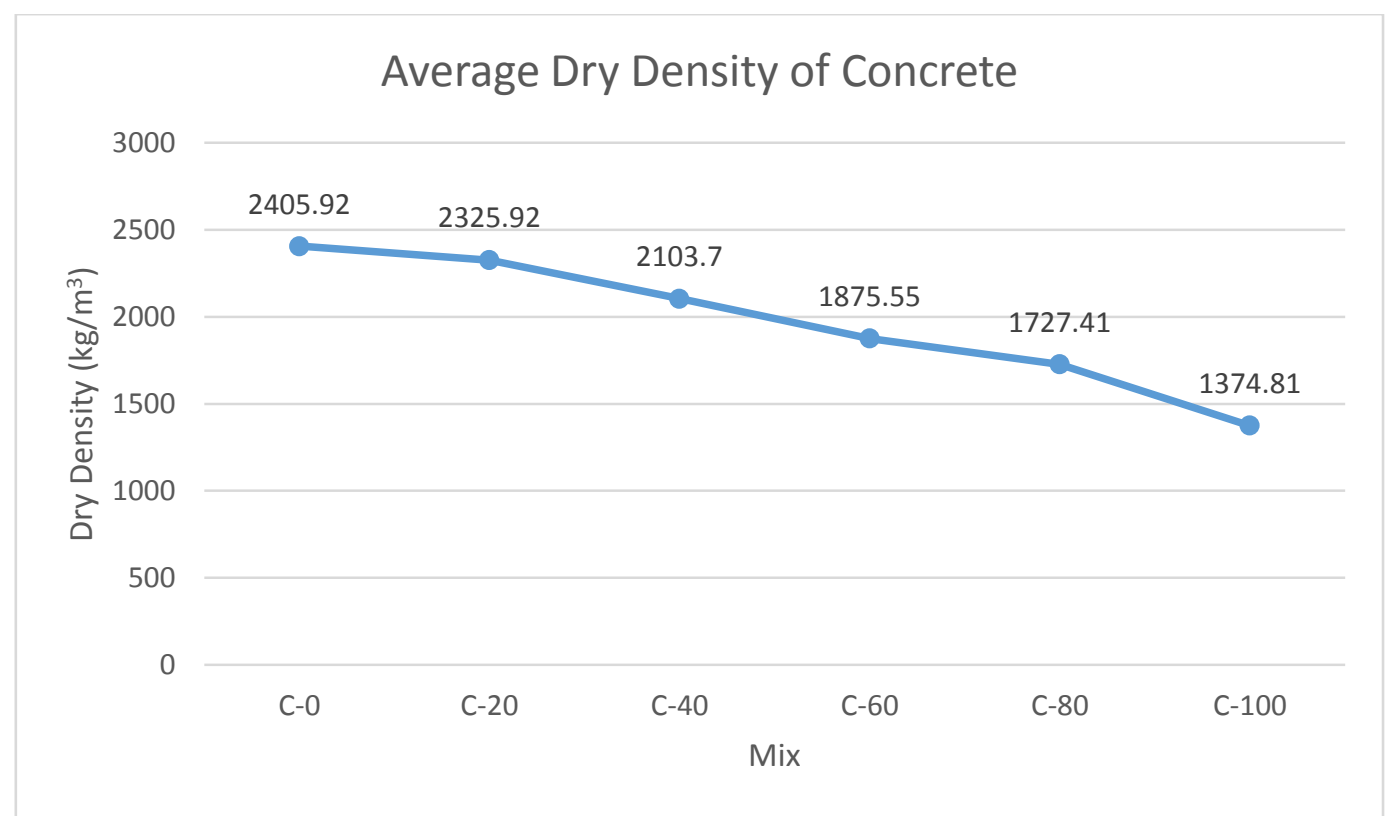

Fig. 2: Average Dry Density of Conrete

With the increase in proportion of Styrofoam in the mix, mass of the specimen decreases.

\section{Conclusion}

From the study carried out, the following observations are drawn:

\begin{tabular}{lrrrrrrrr}
\hline ATP System & $\begin{array}{r}\text { LTB } \\
\text { /100 }\end{array}$ & $\begin{array}{r}\text { Avg } \\
\text { time }\end{array}$ & $\begin{array}{r}\text { Prfs } \\
\text { out }\end{array}$ & $\begin{array}{r}\text { SOTA } \\
\text { Con. }\end{array}$ & $\begin{array}{r}\mu \\
\text { Eff. }\end{array}$ & $\begin{array}{r}\text { CYC } \\
/ 35\end{array}$ & $\begin{array}{r}\text { MZR } \\
/ 40\end{array}$ & $\begin{array}{r}\text { SMO } \\
/ 25\end{array}$ \\
\hline Vampire-LTB 11.0 & 69 & 24.5 & 69 & 0.37 & 28.1 & 23 & 22 & 24 \\
iProver-SInE 0.7 & 67 & 76.5 & 0 & 0.36 & 8.8 & 28 & 14 & 25 \\
SInE 0.4 & 64 & 75.3 & 64 & 0.32 & 8.5 & 26 & 13 & 25 \\
leanCoP-SInE 2.1 & 35 & 110.8 & 35 & 0.23 & 3.2 & 23 & 1 & 11 \\
E-LTB 1.1pre & 18 & 63.4 & 0 & 0.21 & 2.8 & 7 & 9 & 2 \\
EP-LTB 1.1pre & 18 & 77.8 & 18 & 0.21 & 2.3 & 7 & 9 & 2 \\
E-KRH'-LTB 1.1.3 & 0 & - & - & - & - & 0 & 0 & 0 \\
\hline
\end{tabular}

Table 2: LTB division results

- $\quad$ Reduction in mass of concrete by $\mathbf{4 2 . 8 5 \%}$ by full replacement of coarse aggregates.

- Even after completely replacing natural aggregates the compressive strength is higher than the target strength.

Reduction in compressive strength by $\mathbf{2 3 . 4 \%}$ is observed due to full replacement of natural aggregate. 
Experimental Study on Lightweight Concrete with... D. Patel, U. Kachhadia, M. Shah and R. Shah.

\section{References}

Dr. V. Bhaskar Desai and Mr. A. Sathyam, "Some Studies on Strength Properties of Light Weight Cinder Aggregate Concrete", International Journal of Scientific and Research Publications Vol. 4, Issue 2, (2014).

Lakshmi Kumar Minapu, M K M V Ratnam and Dr. U Rangaraju, "Experimental Study on Light Weight Aggregate Concrete with Pumice Stone, Silica Fume and Fly Ash as a Partial Replacement of Coarse Aggregate", International Journal of Innovative Research in Science, Engineering and Technology Vol. 3, Issue 12, (2014) Pages 18130-18138.

T. Parhizkar, M. Najimi and A.R. Pourkhorshidi, "Application of pumice aggregate in structural lightweight concrete", Asian Journal of Civil Engineering (building and housing) VOL. 13, NO. 1 (2012) Pages 43-54.

IS 2386-3, "Method of test of Aggregates for Concrete", (1963)

IS 2386-4, "Method of test of Aggregates for Concrete", (1963)

IS 2386-5, "Method of test of Aggregates for Concrete", (1963)

IS 10262, "Guidelines for concrete mix design proportioning”, (2009) 